\title{
Prognostic role of cell apoptotic rate in prostate cancer: Outcome of a long-time follow-up study
}

\author{
GIUSEPPE DACHILLE ${ }^{1}$, TOMMASO CAI ${ }^{2}$, GIUSEPPE MARIO LUDOVICO ${ }^{1}$, GIOVANNI VESTITA ${ }^{1}$, \\ GIOVANNI PAGLIARULO ${ }^{3}$, GABRIELLA NESI $^{4}$, SANDRA MAZZOLI $^{5}$, FRANCESCA MEACCI $^{5}$, \\ NICOLA MONDAINI ${ }^{2}$, BEATRICE DETTI ${ }^{6}$ and RICCARDO BARTOLETTI ${ }^{2}$
}

\begin{abstract}
${ }^{1}$ Department of Urology, Hospital of Monopoli, Bari; ${ }^{2}$ Department of Urology, University of Florence; ${ }^{3}$ Department of Robotic Surgery, Hospital La Madonnina, Bari; ${ }^{4}$ Department of Pathology and Oncology, University of Florence; ${ }^{5}$ STD Centre, Santa Maria Annunziata Hospital, Florence; ${ }^{6}$ Department of Radiation Oncology, University of Florence, Florence, Italy
\end{abstract}

Received July 16, 2007; Accepted September 14, 2007

\begin{abstract}
The tumour apoptotic pattern is described as a good predictor of outcome in patients with prostate cancer (PCa). So far no authors have evaluated the role of apoptotic characteristics in patients who have undergone radical prostatectomy (RRP) alone. The aim of the present study is to estimate the prognostic role of the apoptotic index (AI) in a group of patients with prostatic adenocarcinoma subjected to RRP with no adjuvant therapy. Fifty patients underwent RRP according to standardised techniques and the surgical specimens were analysed histologically. In order to evaluate the AI and correlate these results with the follow-up data, we used a standardised apoptotic regulatory terminal deoxynucleotidyl transferase-mediated biotinylated deoxyuridinetriphosphate-biotin nick end-labelling technique (Becton Dickinson Immunocytometry Systems, San Jose, CA, USA). The mean follow-up period was 66 months. Significant correlations were found between the AI and pathological features, such as stage $(\mathrm{p}<0.001)$ and grade $(\mathrm{p}<0.001)$. Out of 50 patients, 13 (26\%) had biochemical recurrence and clinical disease progression, with an AI of 1.93 (range, 0.765.22), while 37 patients (74\%) who did not report any disease progression, had an AI of 0.58 (range, 0.1-3.12). Furthermore, the AI significantly correlated with status at the end of follow-up $(r=0.75, p=0.002)$, these data being confirmed by Kaplan-Meier curve analysis $(\mathrm{p}<0.001)$. On multivariate analysis, the AI proved to be an independent prognostic factor of progression-free probability $(\mathrm{p}<0.001)$. Our results highlight the utility of $\mathrm{AI}$ analysis in assessing the probability risk of clinical progression in PCa patients who are treated with RRP.
\end{abstract}

Correspondence to: Dr Tommaso Cai, Department of Urology, University of Florence, via dell'Antella, 58-50011 Florence, Italy E-mail: ktommy@libero.it

Key words: apoptosis, TUNEL, apoptotic index, prostate cancer, radical prostatectomy

\section{Introduction}

It is estimated that in 2007, prostate cancer (PCa) will be the most common malignancy in males, with 218,890 new cases and 27,050 deaths. Moreover, PCa alone accounts for approximately $29 \%$ of cases in men (1). Due to the widespread introduction of the PSA test as an additional screening test (2) and the lowering of the PSA threshold from 4 to $2.5 \mathrm{ng} / \mathrm{ml}$ (3), $91 \%$ of all new cases of PCa are expected to be diagnosed at local or region stages (1). Indeed, PCa continues to be one of the most common fatal cancers (9\% of all cancer deaths) (1) and is today an important social and economic issue. Even if the pathological stage, Gleason score, surgical margin status and tumour volume are the most commonly accepted prognostic factors after radical prostatectomy, the optimum control and management of patients with $\mathrm{PCa}$ is principally contingent on appropriate risk-group stratification based on the correct assessment of biological and clinical features. The ability to predict the true tumour biological potential could facilitate the choice of treatment and improve patient survival rates and quality of life. To increase understanding of the cellular mechanisms underlying the development of PCa and its natural history, various potential molecular markers, in addition to standard prognostic parameters, have been described over recent years (4-6). Much information on the natural history of PCa has also been obtained by analysing apoptosis regulation. Several authors have demonstrated that the tumour apoptotic pattern is a good prognostic marker of outcome in patients affected by PCa (7) as well as other carcinomas, such as salivary malignancies (8) or bladder cancer (9). Moreover, the percentage of apoptotic cells, analysed by using a standardised apoptotic regulatory terminal deoxynucleotidyl transferase (TdT)-mediated biotinylated deoxyuridine-triphosphate (dUTP)-biotin nick end-labelling (TUNEL) technique, has been established as a powerful prognostic marker in numerous neoplasms (8-11). In particular, TUNEL analysis was used by Colecchia et al to evaluate the pathological changes of $\mathrm{PCa}$ in patients undergoing androgen ablation therapy, thus demonstrating that after three months of therapy these neoplasms showed regressive epithelial alterations with an increase in apoptotic tumour cells (7). 
The importance of apoptotic system analysis has also been confirmed in premalignant prostatic lesions such as highgrade prostatic intraepithelial neoplasia (HGPIN) (12). In this regard, the molecular changes in apoptosis regulators have been proposed as molecular markers of HGPIN and potential candidates for therapeutic targeting/chemoprevention of $\mathrm{PCa}$ at an early stage (12). However, to the best of our knowledge, no studies have been performed to evaluate the prognostic role of $\mathrm{AI}$ in $\mathrm{PCa}$ patients undergoing radical prostatectomy alone. The aim of the present study is to estimate the prognostic role of the AI, by means of the TUNEL technique, in a group of patients affected by adenocarcinoma of the prostate, who have undergone retropubic radical prostatectomy (RRP) with no adjuvant therapy.

\section{Materials and methods}

Study design. In order to evaluate the AI of prostate adenocarcinoma and correlate the results with follow-up data, all consecutive patients who had undergone RRP for histologically demonstrated adenocarcinoma of the prostate at the same urological unit between January 1994 and December 1997 were recruited for this prospective study. The study was approved by the local ethics research committee and was conducted according to the ethical principles laid down in the latest version of the Declaration of Helsinki and in line with good clinical practice (GCP) guidelines. Informed consent was obtained from all patients.

Eligibility criteria. All patients with histologically demonstrated adenocarcinoma of the prostate and willing to comply with the follow-up schedules were selected. Patients with a history of other urological cancers and those who had previously undergone prostate surgery were excluded. Also patients with other urological diseases or those who had undergone neo-adjuvant or early adjuvant therapy, such as hormonal therapy, chemotherapy or radiation therapy, were excluded. Patients who had undergone adjuvant therapy, due to disease progression or biochemical recurrence (PSA $\geq 0.2 \mathrm{ng} / \mathrm{ml}$ ) were considered eligible for the study after the PSA had fallen to $<0.001 \mathrm{ng} / \mathrm{ml}$. The time interval from surgery to progression was recorded. Patients who had undergone neoadjuvant or early adjuvant therapy were excluded in order to obtain a valid assessment of the impact of apoptosis on the biological behaviour of $\mathrm{PCa}$, without influence from other variables.

Surgical treatment technique. All patients underwent RRP, according to the Walsh technique (13). Bilateral iliac-obturator lymph node dissection was performed on all patients, as suggested by the European Association of Urology (EAU) Working Group on Oncological Urology guidelines (14). RRP with pelvic lymph node dissection was performed by a number of different surgeons following standardised techniques.

Histopathological analysis. The pathological review was performed by a single pathologist with experience in urogenital pathology and included the examination of all slides of the radical prostatectomy specimen. In addition to Gleason score, pathological stage [Tumour Node Metastasis (TNM), 2002]
Table I. Patient clinical, laboratory and pathological characteristics.

No. of patients 50

Mean age at time of surgery $( \pm \mathrm{SD})$

Preoperative PSA (ng/ml)

Gleason score - biopsy

2-6

$3+4$

$4+3$

Gleason score - surgical specimen

2-6

$3+4$

$22(44)$

$4+3$

Stage

pT2a

$26(52)$

pT2b

$10(20)$

pT3a

pT3b

Lymph node evaluation

NO

$50(100)$

$\mathrm{N}+$

Positive surgical margins

The clinical and histopathological data of all enrolled patients are shown. Data in parentheses are percentages.

(15), presence of extraprostatic extension, invasion of seminal vesicles and surgical margin status were recorded.

Specimen processing and in situ apoptosis evaluation. A sample section of 30 - to $40-\mu \mathrm{m}$ thickness from each patient was deparaffinised by washing in 2 cycles of toluene for $10 \mathrm{~min}$, dehydrated in a decreasing series of ethanol and finally immersed in phosphate-buffered saline (PBS) for $10 \mathrm{~min}$. The material was then disaggregated with scissors and tweezers and treated with RNase for $30 \mathrm{~min}$ at room temperature. Each specimen was then centrifuged and re-washed with PBS and $50 \mathrm{ml}$ of TUNEL reaction mixture (Becton Dickinson Immunocytometry Systems, San Jose, CA, USA) was added for $1 \mathrm{~h}$ at $37^{\circ} \mathrm{C}$ in the dark. Subsequently, it was re-washed with PBS and centrifuged again. The samples were analysed with cytofluorometry FACS on a logarithmic scale. The apoptotic cells were identified by using TUNEL. Briefly, TUNEL is a cytofluorometric method, described by Gavrieli et al (16), which automatically counts the cells containing DNA fragments typical of the apoptotic process. The terminal deoxynucleotidyl transferase $(\mathrm{TdF})$ catalyses the nucleotide polymerization reaction, during which it inserts dUTP marked with fluorescein on the loose terminal 3-OH of the fragmented DNA molecules. The fluorescein incorporated in the nuclear fragments is then highlighted and quantified by a cytofluorometric flux method. The AI was calculated as follows: AI $(\%)=100 \mathrm{x}$ apoptotic cells/total cells. It was determined by counting 3,000 tumour cells in randomly chosen areas of surgical specimens on a light 


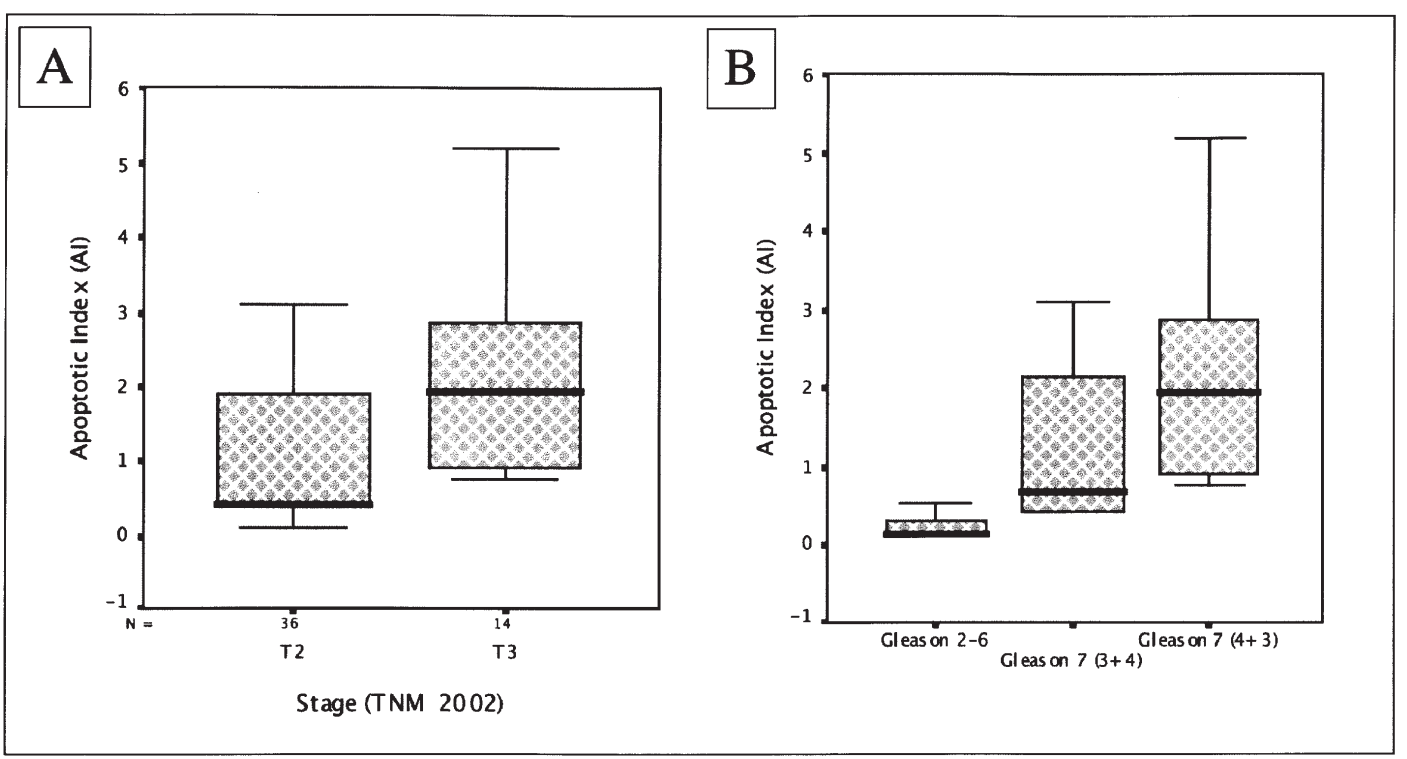

Figure 1. Box-plot shows apoptotic index (AI) according to stage (A) and Gleason score (B).

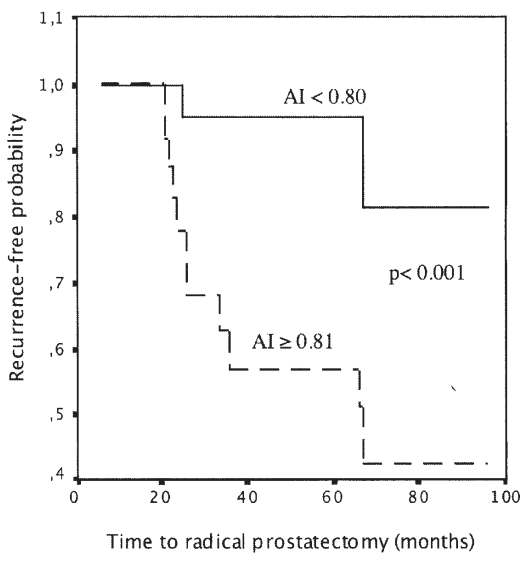

Figure 2. Kaplan-Meier curves illustrating the association between apoptotic index $(\mathrm{AI})$ and overall disease-free patient survival $(\mathrm{p}<0.001, \mathrm{HR}=3.87$; $95 \% \mathrm{CI}=1.98-4.34)$.

microscope at $\mathrm{x} 40$ magnification, as described by Colecchia et al (7).

Patient follow-up. Each patient underwent a standard followup schedule according to the individual tumour characteristics. Biochemical recurrence was defined as a single postoperative PSA $\geq 0.2 \mathrm{ng} / \mathrm{ml}$, following the method of Freedland et al (17). Radionuclide bone scans were performed at the time of biochemical recurrence and thereafter on a yearly basis, or earlier for symptoms suggestive of distant metastasis. A positive bone scan result or other radiographic or histological (lymph node biopsy) evidence of distant failure was used for the diagnosis of distant metastasis. PCa-specific mortality was defined as death in patients with metastasis showing progression after hormonal therapy, or in those not treated with hormonal therapy but with widespread metastases and no other obvious cause of death. The follow-up mean time was 66 months. Patients with no information available at follow-up were excluded from the study.
Statistical analysis. Pearson's coefficient was adopted to evaluate the correlation between the different parameters and Fisher's exact test or Chi-square test was used to assess statistical significance, with $\mathrm{p}<0.05$ accepted as significant. Two-side tests of significance were performed in all analyses. Patients without recurrence were censored at the time of last follow-up or death, and biochemical recurrence-free survival was estimated using the Kaplan-Meier method and compared with groups using the log-rank test or Cox models. By the Kaplan-Meier estimates 95\% confidence intervals (CI) were calculated for the probability of surviving. Risk ratios at $95 \%$ CI were calculated by Cox proportional hazard regression. All statistical tests were performed using SPSS 11.5 for Apple-Macintosh (SPSS, Inc. Chicago, IL).

\section{Results}

Fifty patients were finally enrolled in the present study (mean age, 68.1 years; range, 55 to 75 years). Patient and tumour characteristics are summarised in Table I.

AI results. The mean $\mathrm{AI}$ in 3,000 tumour nuclei was 1.27 ( $\mathrm{SD} \pm 1.15)$. Stratified by stage, the AI results were 1.25 (SD $\pm 0.97)$ for $\mathrm{pT} 2$ and $2.10(\mathrm{SD} \pm 1.2)$ for $\mathrm{pT} 3$, and according to Gleason Score (GS), 0.21 ( $\mathrm{SD} \pm 0.14$ ) for GS 2-6, 1.05 $(\mathrm{SD} \pm 0.14)$ for $\mathrm{GS} 3+4$ and $2.13(\mathrm{SD} \pm 1.2$ ) for $\mathrm{GS} 4+3$ (Fig. 1). Significant correlations were demonstrated between the AI and pathological findings, such as stage $(\mathrm{p}<0.001)$ and grade $(\mathrm{p}<0.001)$.

Follow-up results. At the end of follow-up (mean, 66 months), 13 out of 50 patients $(26 \%)$ had biochemical recurrence and clinical disease progression with PSA $\geq 0.2 \mathrm{ng} / \mathrm{ml}$ (mean, $1.3 \mathrm{ng} / \mathrm{ml}$ ) and positive bone scan findings (mean time to progression, 36 months). These patients underwent combined anti-androgen blockade therapy (therapy with an LHRH analogue and an anti-androgen). Overall 37 out of the 50 $(74 \%)$ patients were alive without any evidence of disease. 
Table II. Multivariate analysis results of factors affecting recurrence risk in all enrolled patients.

\begin{tabular}{|c|c|c|}
\hline Categories (variables) & $\begin{array}{l}\text { No. of recurrence-free patients / } \\
\text { no. of total patients }(\%)\end{array}$ & $\begin{array}{c}\text { Multivariate analysis (p) } \\
\text { HR }(95 \% \text { CI })\end{array}$ \\
\hline Age & & 0.721 \\
\hline$<65$ years & $16 / 23(69.5)$ & $0.84(0.40-0.99)$ \\
\hline$\geq 65$ years & $21 / 27(77.7)$ & $0.80(0.54-1.10)$ \\
\hline Preoperative PSA (ng/ml) & & 0.007 \\
\hline$<10$ & $17 / 28(60.7)$ & $1.03(0.65-1.70)$ \\
\hline$\geq 10$ & $20 / 22(90.0)$ & $5.50(4.30-7.69)$ \\
\hline Gleason score - biopsy & & 0.013 \\
\hline$<7$ & $5 / 14(35.7)$ & $1.63(1.1-1.80)$ \\
\hline$\geq 7$ & $32 / 36(88.8)$ & $3.33(2.70-4.30)$ \\
\hline Gleason score - surgical specimen & & 0.009 \\
\hline$<7$ & $2 / 10(20)$ & $0.90(0.60-1.14)$ \\
\hline$\geq 7$ & $35 / 40(87.5)$ & $4.43(3.31-6.01)$ \\
\hline Stage & & 0.001 \\
\hline pT2 & $25 / 36(69.4)$ & $1.03(0.68-1.20)$ \\
\hline$>\mathrm{pT} 2$ & $12 / 14(85.7)$ & $2.21(1.47-3.97)$ \\
\hline Positive surgical margins & & 0.008 \\
\hline Yes & $4 / 5(80.0)$ & $5.31(3.46-6.65)$ \\
\hline No & $33 / 45(73.3)$ & $0.89(0.01-1.20)$ \\
\hline Apoptotic index & & $<0.001$ \\
\hline$\leq 0.81$ & $14 / 26(53.8)$ & $1.85(1.0-2.45)$ \\
\hline$>0.81$ & $23 / 24(95.8)$ & $3.69(3.36-4.23)$ \\
\hline
\end{tabular}

Data in parentheses are percentages. HR, hazard ratio; 95\% CI, 95\% confidence interval.

Correlation with AI results and follow-up data. The AI was 0.58 (ranging from 0.1 to 3.12 ) in 37 patients without biochemical recurrence or clinical progression, while it was 1.93 (ranging from 0.76 to 5.22 ) in patients with disease progression, showing a correlation between AI and status at the end of follow-up ( $\mathrm{r}=0.75, \mathrm{p}=0.002)$. In addition, Kaplan-Meier curve showed a significant association between progression-free status and AI (p<0.001) (Fig. 2).

Univariate and multivariate analysis. At univariate analysis, Gleason score, pathological stage, and PSA prior to RRP significantly correlated with progression-free probability $(\mathrm{p}=0.009, \mathrm{p}=0.001, \mathrm{p}=0.007$, respectively). At multivariate analysis, the AI $(\mathrm{p}<0.001)$ was identified as an independent prognostic factor of progression-free probability (Table II).

\section{Discussion}

Apoptosis (programmed cell death) is a tightly regulated and selective physiological process that governs the removal of supernumerary or defective cells (18). Recently, it has also been established that disturbance of proliferation and apoptosis are essential events in early carcinogenesis in neoplastic prostate cells (19). Several authors have clearly demonstrated that apoptosis pattern evaluation has clinical importance in urological practice, showing that the clinical progression of $\mathrm{PCa}$ is associated with increased cell proliferation and decreased apoptosis $(7,20)$. It is also important to measure the AI in $\mathrm{PCa}$ or other cancers to verify the efficacy of the anti-cancer agents used (21). The presence of apoptosis after combined endocrine therapy is a well-known phenomenon $(22,23)$. However, most published studies were performed on patients undergoing either radical prostatectomy in association with adjuvant therapy or hormonal therapy alone. In the present study, apoptosis, evaluated as AI with the TUNEL technique seems to be of use as a predictor of biochemical recurrence or clinical progression in patients subjected to radical prostatectomy alone $(\mathrm{p}<0.001)$. AI correlated well with pathological stage and Gleason grade ( $<<0.001$ and $\mathrm{p}<0.001$, respectively), as reported by other authors (7). These findings suggest that increased programmed cell death is a feature of the increasing malignant potential that is associated with higher Gleason score in PCa (24). In comparing the AI with follow-up data, we noted a significant correlation between progression-free probability and AI $(\mathrm{p}<0.0001)$. These findings were also confirmed by Kaplan-Meier curves $(\mathrm{p}<0.001)$ and multivariate analysis $(\mathrm{p}<0.001)$ and are in accordance with other reports highlighting the role of $\mathrm{AI}$ in predicting progression in $\mathrm{PCa}$ patients $(25,26)$. Thus, the most relevant fact in this study is that AI evaluation was performed on selected patients who had undergone RRP with no neo-adjuvant or early adjuvant therapy. This patient selection may be helpful in evaluating 
the real impact of apoptosis on patient outcome evaluation. In a study performed on core needle biopsy specimens with PCa, Karaburun Paker et al reported that there was no significant relation between the expression of the apoptosis regulating genes bcl-2 and p53 and Gleason score in PCa (27). However, our study differs from that of Karaburun Paker because of the laboratory technique used. Zeng et al showed that the identification of apoptotic regulators in premalignant lesions of the prostate may have prognostic significance in disease progression, as well as therapeutic value for targeting PCa (28). These results are in line with our data indicating the clinical prognostic importance of AI evaluation in PCa outcome. However, as Armas et al (22) postulated, data concerning the AI could be underestimated because of the possible completion of hormone regulated apoptosis after three months of therapy, the heterogeneity of androgen sensitivity among subpopulations of tumour cells, or the difficulty in detecting apoptosis by the observation of nuclear morphology in haematoxylin and eosin-stained sections. In addition, the use of apoptosis rate analysis should be considered in association with conventional prognostic factors, because of its low-cost performance ( $\$ 449$ for 1 kit: kit capacity, 40 assays) (http://www.upstate.com/ browse/productdetail.asp?ProductID=17-141), independent of the laboratory technician's skill $(29,30)$. To the best of our knowledge this is the first study to establish a correlation between apoptosis pattern and outcome in patients with $\mathrm{PCa}$ after RRP that are not receiving any neo-adjuvant or early adjuvant treatment.

\section{Acknowledgments}

Special thanks to Professor John Denton for manuscript language revision.

\section{References}

1. Jemal A, Siegel R, Ward E, Murray T, Xu J and Thun MJ: Cancer statistics, 2007. CA Cancer J Clin 57: 43-66, 2007.

2. Jemal A, Clegg LX, Ward E, Ries LA, Wu X, Jamison PM, Wingo PA, Howe HL, Anderson RN and Edwards BK: Annual report to the nation on the status of cancer, 1975-2001, with a special feature regarding survival. Cancer 101: 3-27, 2004.

3. Catalona WJ, Loeb S and Han M: Viewpoint: expanding prostate cancer screening. Ann Intern Med 144: 441-443, 2006.

4. Momii Y, Izumi H, Shiota M, Onitsuka T, Abe T, Kobayashi H, Miyamoto N, Uchiumi T and Kohno K: p73gamma transactivates the p21 promoter through preferential interaction with the p300/CBP-associated factor in human prostate cancer cells. Oncol Rep 18: 411-416, 2007.

5. Winnes M, Lissbrant E, Damber JE and Stenman G: Molecular genetic analyses of the TMPRSS2-ERG and TMPRSS2-ETV1 gene fusions in 50 cases of prostate cancer. Oncol Rep 17: 1033-1036, 2007

6. Ittmann MM: Chromosome 10 alterations in prostate adenocarcinoma (review). Oncol Rep 5: 1329-1335, 1998.

7. Colecchia M, Frigo B, Del Boca C, Guardamagna A, Zucchi A, Colloi D and Leopardi O: Detection of apoptosis by the TUNEL technique in clinically localised prostatic cancer before and after combined endocrine therapy. J Clin Pathol 50: 384-388, 1997.

8. Nagler RM, Kerner H, Ben-Eliezer S, Minkov I and Ben-Itzhak O: Prognostic role of apoptotic, Bcl-2, c-erbB-2 and p53 tumor markers in salivary gland malignancies. Oncology 64: 389-398, 2003.

9. Karam JA, Lotan Y, Karakiewicz PI, Ashfaq R, Sagalowsky AI, Roehrborn CG and Shariat SF: Use of combined apoptosis biomarkers for prediction of bladder cancer recurrence and mortality after radical cystectomy. Lancet Oncol 8: 128-136, 2007.
10. Ben-Izhak O, Laster Z, Araidy S and Nagler RM: TUNEL - an efficient prognosis predictor of salivary malignancies. Br J Cancer 96: 1101-1106, 2007.

11. Santini D, Tonini G, Vecchio FM, Borzomati D, Vincenzi B, Valeri S, Antinori A, Castri F, Coppola R, Magistrelli P, Nuzzo G and Picciocchi A: Prognostic value of Bax, Bcl-2, p53, and TUNEL staining in patients with radically resected ampullary carcinoma. J Clin Pathol 58: 159-165, 2005.

12. Zeng L and Kyprianou N: Apoptotic regulators in prostatic intraepithelial neoplasia (PIN): value in prostate cancer detection and prevention. Prostate Cancer Prostatic Dis 8: 7-13, 2005.

13. Schlegel PN and Walsh PC: Neuroanatomical approach to radical cystoprostatectomy with preservation of sexual function. J Urol 138: 1402-1406, 1987.

14. Aus G, Abbou CC, Bolla M, Heidenreich A, Schmid HP, van Poppel H, Wolff $\mathbf{J}$ and Zattoni F; European Association of Urology: EAU guidelines on prostate cancer. Eur Urol 48: 546-551, 2005.

15. American Joint Committee on Cancer. Prostate (sarcomas and transitional cell carcinomas are not included). In: AJCC Cancer Staging Manual. 6th edition. New York, Springer-Verlag, 309-316, 2002.

16. Gavrieli Y, Sherman Y and Ben-Sasson SA: Identification of programmed cell death in situ via specific labeling of nuclear DNA fragmentation. J Cell Biol 119: 493-501, 1992.

17. Freedland SJ, Partin AW, Humphreys EB, Mangold LA and Walsh PC: Radical prostatectomy for clinical stage T3a disease. Cancer 109: 1273-1278, 2007.

18. Akyurek N, Ren Y, Rassidakis GZ, Schlette EJ and Medeiros LJ: Expression of inhibitor of apoptosis proteins in B-cell nonHodgkin and Hodgkin lymphomas. Cancer 107: 1844-1851, 2006.

19. Ananthanarayanan V, Deaton RJ, Yang XJ, Pins MR, Gann PH. Alteration of proliferation and apoptotic markers in normal and premalignant tissue associated with prostate cancer. BMC Cancer 6: 73, 2006.

20. Koivisto P, Visakorpi T, Rantala I and Isola J: Increased cell proliferation activity and decreased cell death are associated with the emergence of hormone-refractory recurrent prostate cancer. J Pathol 183: 51-56, 1997.

21. Sarkar FH and Li Y: Markers of apoptosis. Methods Mol Med 120: 147-160, 2006.

22. Armas OA, Aprikian AG, Melamed J, Cordon-Cardo C, Cohen DW, Erlandson R, et al: Clinical and pathobiological effects of neoadjuvant total androgen ablation therapy on clinically localized prostatic adenocarcinoma. Am J Surg Pathol 18: 979-991, 1994.

23. Montironi R, Magi-Galluzzi C, Muzzonigro G, Prete E, Polito M and Fabris G: Effects of combination endocrine treatment on normal prostate, prostatic intraepithelial neoplasia and prostatic adenocarcinoma. J Clin Pathol 47: 906-913, 1994.

24. Aihara M, Truong LD, Dunn JK, Wheeler TM, Scardino PT and Thompson TC: Frequency of apoptotic bodies positively correlates with Gleason grade in prostate cancer. Hum Pathol 25: 797-801, 1994.

25. Szostak MJ, Kaur P, Amin P, Jacobs SC and Kyprianou N: Apoptosis and bcl-2 expression in prostate cancer: significance in clinical outcome after brachytherapy. J Urol 165: 2126-2130, 2001.

26. Mackey TJ, Borkowski A, Amin P, Jacobs SC and Kyprianou N: bcl-2/bax ratio as a predictive marker for therapeutic response to radiotherapy in patients with prostate cancer. Urology 52: 1085-1090, 1998.

27. Karaburun Paker S, Kilicarslan B, Ciftcioglu AM, Oztekin S, Sargin FC, Erdogru T and Baykara M: Relationship between apoptosis regulator proteins (bcl-2 and p53) and Gleason score in prostate cancer. Pathol Oncol Res 7: 209-212, 2001.

28. Zeng L, Rowland RG, Lele SM and Kyprianou N: Apoptosis incidence and protein expression of p53, TGF-beta receptor II, p27Kip1, and Smad4 in benign, premalignant, and malignant human prostate. Hum Pathol 35: 290-297, 2004.

29. Yang Y, Ikezoe T, Takeuchi T, Adachi Y, Ohtsuki Y, Koeffler HP and Taguchi H: Zanthoxyli Fructus induces growth arrest and apoptosis of LNCaP human prostate cancer cells in vitro and in vivo in association with blockade of the AKT and AR signal pathways. Oncol Rep 15: 1581-1590, 2006.

30. Allen RT, Hunter WJ III and Agrawal DK: Morphological and biochemical characterization and analysis of apoptosis. $\mathrm{J}$ Pharmacol Toxicol Methods 37: 215-228, 1997. 